\title{
Private external funding of universities: Blind alley or new opening?
}

\section{Christoph Badelt ${ }^{1,2}$}

Received: 27 May 2019 / Accepted: 21 October 2019 / Published online: 8 November 2019

(c) The Author(s) 2019

\begin{abstract}
Of late, the problems of private external, or third-party funding of universities have been the subject of much debate, even at universities of economics and business. Given the constraints on government funding, politicians are looking increasingly to this source, with university leaders (rectors, deans, department heads) frequently being set targets for increasing income from it. Yet it is important to distinguish between different types of external funds. Moreover, their advantages and potential drawbacks must be weighed up. This paper seeks to do that, against the background of the author's more than 13 years as Rector of Vienna University of Economics and Business (WU). Much of the paper thus draws rather less on theory than on that practical experience.
\end{abstract}

Keywords Private external funding · Universities - Governance · Potentials: threats · Strategies $\cdot$ Reputation, autonomy

JEL Classification $\cdot \mathrm{M} 10 \cdot 122 \cdot 123 \cdot 128$

Christoph Badelt

christoph.badelt@wifo.ac.at

1 Institute for Social Policy, Vienna University of Economics and Business (WU), Welthandelsplatz 1/D4, 1020 Vienna, Austria

2 Österreichisches Institut für Wirtschaftsforschung (WIFO), Arsenal 20, 1030 Vienna, Austria 


\section{External funding: towards a typology}

\subsection{From donations to business investments}

The arrangements under which universities may receive external funds form a spectrum ranging from business deals at one end to gifts at the other. Depending on their location on this spectrum, there are massive variations in the way such monies are treated by the law or regarded from a university policy standpoint. ${ }^{1}$

A gift, or donation, is generally an act of pure philanthropy. In this case, money is given to a university with no conditions attached. In direct contrast, under a contractual business deal the university must provide a quid pro quo which it and the funding party consider to be equal in value to the funds received. Universities enter into many different forms of such arrangements. For example, they may provide continuing education in return for fees. Or they may be paid for carrying out commissioned research projects that have been previously defined and costed.

The numerous hybrids of these two archetypal arrangements raise serious considerations for tax law, corporate law and anti-corruption legislation. They comprise the many different types of fundraising or sponsorship under which private financiers provide universities with money and receive something in return. That 'something' might, for example, be the advertising benefit derived from the display of a company's logo. The value of such a benefit is often hard to establish, and may well, quite intentionally, be less than the sum received by the university. That is true of support given to seminars or one-off university events, but may also apply to more extensive, longer-term sponsorship arrangements, for instance the sponsoring of lecture halls. Even the award of honorary degrees in direct or indirect response to the grant of larger amounts falls into this category.

Here it is important to point out a common source of terminological confusion. The specialist literature in English restricts the term 'sponsorship' to cases where the benefit received by the sponsor (e.g. through display of a plaque featuring a company name) is of lower value than the funds received by the university. By contrast, under Austrian law the German term 'Sponsoring' is used specifically where the two values are equal. Should that not be the case, a public university could even face prosecution under anti-corruption laws.

\section{The uses to which funds may be put}

The value of private external funds to a university is affected by the extent to which they are earmarked for a particular purpose. From a recipient university's point of view, the optimal situation is undoubtedly that where funding is provided without any stipulations as to its use, so that the university is free to use the money how and when it wants.

\footnotetext{
${ }^{1}$ The rector of an Austrian university is its chief executive, equivalent to a vice-chancellor in the UK or a university president in the US.
} 
In some cases, the purpose for which funds are intended is stipulated in very broad terms only, so that there is considerable discretion as to how they are actually applied. Thus a chair in a particular subject area may be endowed without stipulating exactly what its holder must work on. Alternatively, external funds may be designated for awarding grants or providing support to members of particular groups (e.g., for the advancement of women). Within these parameters the university can then pursue its own policy goals.

On other occasions, universities have much less freedom in applying external funds, which may be earmarked to finance certain specified activities. For example, the classes WU Wien offers during vacations (its so-called Summer and Winter Universities) are funded by grants from firms. Although the funding does not cover the full cost of the classes, it is agreed that these will include a reference to the donor firms.

\section{Providers and recipients of external funds}

In practice, the issues associated with external funding vary with the institutional and legal status of its source, the funder, and its recipient. In the simplest case, the former is an individual who makes a donation from their private fortune. This situation poses the fewest technical problems because the decision processes involved are straightforward, and there is no specific requirement for accountability to third parties. It arises typically when the donor has a strong emotional attachment to the university concerned, for example as an alumnus. Frequently, before providing funds, he or she has had a lengthy personal relationship with the university's authorities or with individual university members. The provision of funds by a foundation, especially a charitable one, can be similarly unproblematic if its charter stipulates exactly the purpose to which the funds are to be put, and if the procedures to be followed, including those for audit, are subject to clearly defined rules.

The issues become more complex if the funding person or institution does not own the funds and must therefore consider the need to account for their decision to third parties, for example a supervisory board. This situation can arise with associations as well as companies, whose CEO and other managers must observe the relevant corporate governance rules in granting funds to universities. In essence that applies whether or not the university provides a quid pro quo in return, although the nature of accountability or audit is generally different in the two cases.

Also worthy of mention here is funding bequeathed as a legacy. In this case, the deceased person's executors must follow the rules that are usually set out in the will. Here too the bequest will generally have been preceded by a lengthy relationship between the university and the deceased. Thus, for example, effectively cultivating alumni links can lead to a university benefiting in this way.

As regards the possible recipients of funds, these may be individuals (e.g. researchers), university departments and institutes, or university management acting on behalf of their university. There are considerable practical distinctions between the three cases. In particular, the implications under the Austrian Universities Act are different, which is of especial importance when a service is provided in return 
for external funds. If these are received by an individual, for instance to finance a research project, then he or she is personally responsible for providing the agreed quid pro quo. On the other hand, if a chair is endowed, then it is usual and legally correct that the university management assume responsibility for establishing the professorship. As soon as a professor is appointed, however, these managers can no longer be responsible for his or her activities. It is therefore necessary to devise a way of defining the responsibilities of the chair's occupant-which can cause very significant complications for the university.

\section{External funding in kind}

Although in common parlance 'external funds' are generally understood to mean cash, it is actually perfectly usual for universities to receive such funding in kind, in the form of rooms, documentation for meetings, IT or other equipment, vehicles and so on. The promotional value to the provider of such material donations is vastly increased if they can be clearly identified with the donor (e.g. by a firm's logo on furniture or IT equipment); attaching an acknowledgment of their source is the best alternative, but a poor one. From the university's perspective, it is often easier to attract funding in kind rather than in cash since it is easier for the provider firm to justify such donations internally.

In the broadest sense, seconding staff to universities can also be seen as a form of private external funding. In such cases, research assistants or administrative staff, for example, employed by the funding institution (e.g. a firm or professional association) carry out tasks for the university concerned. This raises complex issues relating to labour law and university legislation.

\section{The reasons why universities seek external funding}

It seems natural to assume that the primary motivation for universities to seek external funding is financial. And, indeed, whenever public funding is scarce or unreliable, it is vital that universities also have access to alternative, private sources. In these circumstances, funds which are not earmarked for any specific purpose are particularly attractive as they may be used flexibly to augment or complement the total budget.

From a commercial perspective, it makes sense for a university to reduce its dependence on individual sources of funding, even if it is hard for public universities to do so. As a result, university leaders are constantly in search of external funds to stabilise or enhance the budgetary situation. They are especially keen to attract undesignated funding, the argument they typically use being the high reputation of their university or a particular department.

However, the opposite approach is also found. In other words, the university's aim may be to attract funding for a concrete project, such as the construction of a new building or laboratory, or the establishment of a particular academic unit. Here, the search for external funding is aimed at enabling the realisation of some cherished 
project that otherwise could not be financed. Experience shows this approach to be more fruitful than seeking non-earmarked funding. The reason is that the project's inherent attractiveness can be used to persuade potential donors, who also have the prospect of seeing the material result of their efforts. Thus it is easier to obtain funding for a specific research project-especially if the donor is also convinced of the pressing need for it - than funding for general, unspecified research.

On occasion, this approach to fundraising is also used to provide the basic funding for entire academic units, such as research institutes or laboratories. A good example is the Competence Center for Central and Eastern Europe at WU. For many years it was funded by companies with a particular interest in research about the region, but which were also interested in recruiting graduates from there or prepared to work there.

External funding acquires a special character when it is provided in the context of a long-standing relationship. In such cases, the recipient university's efforts are focused on maintaining this long-term cooperation, which extends far beyond the purely financial. Thus on its new campus WU Vienna has introduced a system of lecture-hall sponsorship, which was intended not only to raise funds but also to document cooperations with various major Austrian companies. Indeed, for universities of economics and business it is essential to be involved in partnerships with important firms.

If a university has a lengthy, stable relationship with a major enterprise, then, within that context, it is common practice to establish each year a particular use for funding, and sometimes also the extent of overall support. Cooperation then generally extends beyond the financial sphere. It may aim, for example, to identify research topics of relevance for professional practice or to obtain access to data.

One potential side effect of a lengthy support agreement that is not to be underrated is that it ensures the maintenance of personal contacts between top executives and university leaders. Thus WU benefits from a number of foundations set up by large companies, in particular financial service firms. The support received from them may not be especially large in monetary terms. However, the foundations' charters ensure that leaders of the endowing company and the university meet regularly at board meetings to exchange experiences. This serves automatically as a means of maintaining contacts.

\section{Positive experiences with providers of private external funds}

The types of possible relationships between universities and private funders are legion, but a few have proved to be especially advantageous for universities. The ideal situation from their point of view is one where they can rely for the support of their activities on foundations that operate with a long-term horizon, and may even be set up expressly for that purpose. In WU's case, there are two such associations: the "WU Board of Trustees" (Kuratorium zur Förderung der Wirtschaftsuniversität Wien) and the "WU Anniversary Foundation" ("WU-Jubiläumsstiftung").

The university then benefits from an endowment, a stock of invested capital that generates a reliable income stream-even if in times of low interest rates the 
stream may run rather dry. It can plan on the basis of this steady inflow and usually also has a say in how the funds are used. Meanwhile, the foundation's decision-makers also help in maintaining contacts with corporate leaders and public figures. Supporting institutions of this kind also exist at the level of departments or other academic units, albeit mostly on a smaller scale. The money received can be used for purposes whose funding from public sources is impossible, politically undesired or inappropriate for some other reason.

Another highly successful way of acquiring external funds is through longterm cooperation arrangements with individual companies. These are usually governed by a framework agreement that lays down the extent of the support to be provided and the basic aims of cooperation. This is then implemented by means of more detailed annual provisions that establish the funds to be granted in a particular period. In most cases, the funder is anxious to achieve visibility at university level, be it by holding events there, by sponsoring a conference or series of lectures, etc.

A particular example of long-term external funding is the endowed chair. In practice, such arrangements are truly successful only under certain circumstances. Experience at WU suggests that endowments are effective above all where they complement or reinforce existing strengths or priorities. Thus an endowed chair makes most impact when the university itself invests in it or in its immediate subject area. Chairs that are not anchored in this way, but set up merely because some funder is prepared to provide the necessary money, are generally less successful since continued funding is very rarely guaranteed.

In Austria, universities are in the position to anchor endowed chairs as just described because they enjoy the autonomy to establish professorships within their own area of activity. Prior to the 2002 Universities Act, they did not have that right, and so lacked autonomy when the first endowed chairs were established in the country. It therefore made perfect sense to establish such professorships in areas where no chair had been officially approved or funded. At that time, they were an unbureaucratic way of being innovative.

To give an example, the first endowed chair established at WU was that of Startup Research and Entrepreneurship. It was set up at a time when professors' posts had to feature in the federal government's personnel plan, which in practice meant that it could often take years to establish them. It was therefore natural that private funders free from budgetary and bureaucratic restrictions should have the role of setting up new chairs quickly. In the present legal situation, it is a university's own responsibility to identify such needs and provide the necessary funds. Its initiative can then be supported and strengthened by the endowment of a chair.

\section{Problems and criticism}

The exaggerated hopes often expressed in political debate about the beneficial effects of private external funding generally ignore a number of problem areas. These will be summarised in the remainder of the paper. 


\subsection{The lack of a philanthropic tradition in Austria}

Unlike the English-speaking world, Austria has no strong tradition of charitable support by wealthy patrons, and none at all in the areas of science and research. That is especially regrettable because funding that universities receive free of conditions as to its use is of particular value and gives rise to virtually no problems.

There are various reasons for this limited willingness to make donations in the service of science. One factor not to be underestimated is that, relative to Britain and America, private fortunes are smaller and the number of genuinely rich individuals much lower in Austria. Connected to that is the lack of a philanthropic tradition, itself the result of a different conception of the respective responsibilities of the public and private sectors. In the US, for example, a well organised 'independent sector' brings together many types of potential private donors, both individuals and corporate bodies, and sees its role as representing the interests of 'philanthropy'. That alone shows the depth of the cultural gulf that separates Austria from the Englishspeaking world.

The comparatively low level of philanthropic activity in Austria can also be seen as resulting from the relevant legal provisions. For the legislation relating to private foundations is primarily concerned with the transfer of capital from one generation to the next, rather than with its accumulation in the interest of public service. The preferential treatment for tax purposes currently accorded to donations designed to support science and research cannot compensate for this basic orientation of the law on foundations. That is also the reason why consideration has been given on various occasions to reforming the legislation in order to provide new incentives for philanthropy.

A third ground for the relatively low willingness to donate is associated with the strong role of the state in general, and the high level of taxation in particular. In Austria, almost half of any additional income is taken in tax, and potential funders such as banks, in particular, are additionally subject to special levies, such as the "bank tax' imposed for a number of years following the financial crisis. Against that background, it is hardly surprising that potential funders often feel that they have already 'done their bit' for the community by paying taxes. This feeling also explains why the ever louder demands for greater private engagement, for example in discussions of policy towards the universities, have sometimes met with a sceptical response from those potentially affected.

\subsection{Problems with the 'sustainability' of external funding}

Private external funds for university activities are often regarded by funders as seed capital, with the expectation that before too long the university (or 'the government') will take on responsibility for ongoing funding. Endowed chairs, for instance, are generally funded for a specified period (very often 5 years). By the end of this period, so it is assumed, the university must be in a position either to ensure permanent funding by restructuring its own budget or, alternatively, to secure continuing 
financial support from elsewhere (in Austria, within the framework of its threeyearly funding agreement with the federal government).

This approach is logical from funders' point of view. First, it often matches their understanding of their own role as that of providing a kick-start for particular activities. Second, funders usually have no wish to make an open-ended financial commitment. For firms, even a five-year one is often risky. And even foundations, which finance support from their capital stock, frequently balk at constraining their financial room for manoeuvre too greatly by making long-term commitments.

This leaves universities on the horns of a dilemma. For public funds too are increasingly often granted only 'on a project basis' - and so for a limited period. This approach is meant to incentivise universities to continuously monitor whether their expenditure is being employed sensibly and to create a positive climate for structural change within them. This may make sense in financial management terms. But it overlooks the fact that top class researchers are interested only in tenured posts and are thus simply not available for fixed-term projects. Nor is it only a question of individual researchers. A department whose funding is assured only for a few years at a time, and whose existence is therefore called into question every three or 4 years, can never offer an attractive environment for excellent basic research.

Of course, private firms outside the world of research must also live with the uncertainty that comes from having to ensure their existence by generating returns in the market. That is why they usually have limited sympathy for universities' case. However, companies tend to react to a fall in returns by adjusting personnel numbers accordingly - that is, by firing staff. Here is where the comparison between universities and commercial enterprises comes to an end. Suppose that a university faced with a decline in its income chose to dismiss good, experienced researchers, some perhaps professors. It would very soon lose its reputation as an employer of top research staff - quite simply because the best universities and research institutes can offer secure, tenured contracts. In other words, adopting from the private sector the practice of frequently adjusting staff numbers would rob universities of their ability to compete.

\subsection{Governance problems relating to external funding}

As was set out in Section I above, the recipients of external funds may be individual members of university staff, departments or other academic units, or a university itself - which in practice means its management team. Austrian law includes various provisions to support and promote this variety. Thus Section 26 of the Universities Act provides for members of a university's staff to attract external funds in a personal capacity and to make use of them, but to carry out the activities concerned (e.g. a research project) at their university, provided they pay for using its infrastructure. Even so, funds acquired under the conditions of Section 26 remain the property of the person who attracted them. By contrast, Section 27 of the same Act establishes that, while funding paid to a university unit such as a department may be used by the recipient, its legal owner is the university. 
These provisions make it easier for researchers to pursue their activities at a university (and not, say, in an association or a commercial organisation). On the other hand, they give rise to problems that are sometimes both odd and hard to grasp. Moreover, they become more serious the more external funding is attracted. For example, staff recruited with such funds are university employees. Consequently, if a party to a contract governing a Section 27 project fails to fulfil their obligations, or does so tardily, then the university concerned may have to resort to time-consuming, costly dismissal procedures in order to rid itself of a financial burden. Seen from outside, it is also hard to understand that a university may have considerable assets on its books over which it is unable to exercise any control (e.g. as yet unused external funds for a Section 27 research project). It is not uncommon that universities are forced to take on the role of a bank vis-à-vis their employees, for instance when their overall budget is called upon to resolve liquidity problems caused by an external funder's poor payment practices.

Given these issues, external funding can frequently become a source of friction and problems for universities. One obvious example of the former is the needindeed the legal requirement - to make a contribution to the university's overhead costs out of such funds. This is often seen by those affected as a sort of 'tax' on the funds, although it is actually only a matter of cost transparency. On the other hand, external funders sometimes-as is often the case with research funding-require universities to bear some or all overheads themselves. This can have the strange effect that they come under financial pressure because some of their academic units have been particularly successful in attracting external funds.

From time to time, individual departments may even compete with their own university' management team for sponsorship from private funders, commercial ones in particular. This can only be avoided by setting strict guidelines for handling contacts outside the university, something easier said than done.

Finally, we should mention another aspect of governance connected with external funding issues. In countries where private funds make up an important part of universities' income it is common for university leaders, in particular chief executives such as presidents or vice-chancellors, to devote a major portion of their working time-well over half — to fundraising. Indeed, efforts to cultivate contacts over the long term also make heavy demands on their private lives. This situation reflects a very different understanding of what leading a university involves. Unlike Austrian rectors, presidents or vice-chancellor's are only marginally involved in day-to-day academic affairs, which are often the responsibility of another, such as a pro-vicechancellor or provost. In Austria, such a distribution of responsibilities is still very unusual.

\section{External funds and matching grants}

Austrian politicians have recently taken to offering so-called 'matching grants' as an incentive to attract external funding. In other words, a public authority commits itself, for instance, to matching the funds attracted out of public coffers. On occasion, such commitments are made only to certain organisations (e.g. IST Austria), 
which distorts competition between research institutions. In any case, it has difficult to verify empirically the claim that they actually increase the amounts of external funding raised by individual universities. And they certainly generate side effects that are either undesirable or hard to monitor.

As regards the recipients of such support, rather than increasing a university's external fundraising efforts, matching grants may serve merely to shift them towards those areas where such grants are available. Thus existing external funds may be crowded out by those which government has committed to matching. This will have the-perhaps desired-structural impact of shifting a university's priorities towards a particular field. But it need not necessarily raise the amount of external funding attracted since the university's fundraising efforts are simply reoriented.

From the point of view of public authorities, matching grants are very much a two-edged sword. In their pure form these involve an open-ended legal commitment, the total size of which cannot be foreseen in advance. As a result, authorities are unable to plan reliably, and so long-term or large-scale programmes of this type are rare. The only alternative is to cap the total amount of funding available from the outset, and then divide this total among universities according to the external funds these raise. But then universities are rewarded for the relative size of the external funds they raise, not the absolute amount. That was the approach adopted in the original Austrian legislation with the establishment of a so-called 'budget formula', and it was again apparent in the arrangements for so-called 'Higher Education Structural Funds'. How this aspect of university funding is to be regulated in the longer term remains unclear.

\section{Private external funding and funders' influence on teaching and research}

One of the strongest arguments against the use of private money to fund universities' activities is that the providers of such funds could so influence the results of research or the content of degree programmes that the independence of teaching and research might be compromised. This is undoubtedly one of the central issues related to external funding, and is best considered by breaking it down into its component aspects.

First, it is a fact that whenever a particular activity-be it a research project, a conference or a research institute-is funded privately, then the funder inevitably exercises some influence, specifically over the choice of subject. For example, what is investigated, or not investigated, depends at least in part on the funder-and that can be problematic. Yet this issue arises not only when the funder comes from the commercially-oriented private sector, but also in the case of funding from the nonprofit sector or from public bodies. The desire to influence is no weaker in these areas than in private industry. The problem can be avoided only if a university has exclusive decision-making rights with regard to the funds it raises, as is the case with lecture hall sponsorship or funding from associations whose raison d'être is to support it. 
A second aspect of the issue is apparent above all when a chair is endowed. It is the danger that the endowing person or institution will wish to be involved in the choice of the new professor, however this wish may be expressed. Sections 98 and 99 of the Austrian Universities Act, however, stipulate clear procedures for the appointment of professors that are designed to guarantee a balance of powers between certain organs of the university (the appointment commission of the senate) and its head, the Rector. There is no provision for any external involvement, for instance that of a funder, which would thus be illegal.

At WU, there has been no instance as yet of a funder wishing to condition an appointment to an endowed chair. It is nonetheless important that the university makes this principle clear in the negotiations that lead to an endowment. On the other hand, it is sensible and helpful in building confidence between partners that the funder is bound into the ongoing appointment procedure by being kept appropriately informed. After all, it makes no sense to appoint someone who from their very first meeting is set on a confrontation course with the funder. In other words, the problem can be resolved only by a good dose of social intelligence.

The third, and probably most commonly occurring aspect of the influence issue is the possibility the funder or funders may determine, or help to determine the nature of university activities, and thus the results of a research project or the central message of a teaching programme. Put crudely, is it possible for a private funder to 'buy' a university together with its teaching and research? This question is central to the ethics of external funding. And it is one that must be faced not only by universities as organisations, for example when they accept a major donation for a new building or substantial private-sector funding to establish a 'cooperation' with a company. It also affects individual researchers, who may succeed in attracting funds for a particular research project.

It is a dilemma that cannot be completely resolved. However, we can state a few principles that can reduce the danger that research results will be manipulated or the content of teaching influenced. They include the following.

- The contracts under which support is provided, or any other agreements that form the basis on which external funding is granted, must be fully transparent.

- Contractual agreement must exist that any results achieved will be published and thus made available to academic debate.

- The identity of the funder(s) of a particular piece of research work must be absolutely clear to the academic community.

A further point is that less pressure is exercised on the content of research projects or teaching if external funding for them is made available, not directly to the project leader or the member of teachings staff concerned, but to the university as a body, as is the case with endowments or lecture hall sponsorship. Nevertheless, suspicions or concerns about funders' influence on research and teaching content will never be fully allayed. It is thus all the more important that all issues relating to the private funding of universities be handled within a clear regulatory framework that establishes the public purse as the main source of finance for public universities. 
A brief final example will help to explain this principle. In 2013, WU moved to a new campus funded with public money (the total cost was just under $€ 500$ million). At the same time, a sponsorship scheme for lecture halls and other spaces was set up. In return for providing funds, Austrian companies could have a lecture hall or library space named after them, or at least have their support acknowledged next to the room concerned. Once the campus was opened, this scheme brought WU an annual income of around $€ 1.2$ million, while also giving the companies involved clear visibility. Yet the University also wished to make clear the relative importance of private and public funding to the project as a whole. To that end, a plaque was erected in the main hall of WU's Learning Center with the following text:

"The Vienna University of Economics and Business (WU) wishes to express its gratitude to the public, whose contributions have enabled the building of this campus. Without public funding, it would have been impossible to realize one of the fundamental principles enshrined in the Austrian Constitution: the freedom of university research and teaching."

Acknowledgements Open access funding provided by Vienna University of Economics and Business (WU).

Open Access This article is distributed under the terms of the Creative Commons Attribution 4.0 International License (http://creativecommons.org/licenses/by/4.0/), which permits unrestricted use, distribution, and reproduction in any medium, provided you give appropriate credit to the original author(s) and the source, provide a link to the Creative Commons license, and indicate if changes were made.

Publisher's Note Springer Nature remains neutral with regard to jurisdictional claims in published maps and institutional affiliations. 